\title{
Elastic-band traction technique for cannulating intradiverticular papilla during endoscopic retrograde cholangiopancreatography
}

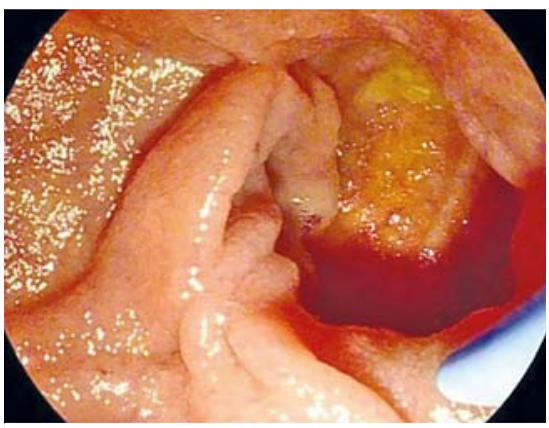

- Fig. 1 Endoscopic view of intradiverticular papilla.

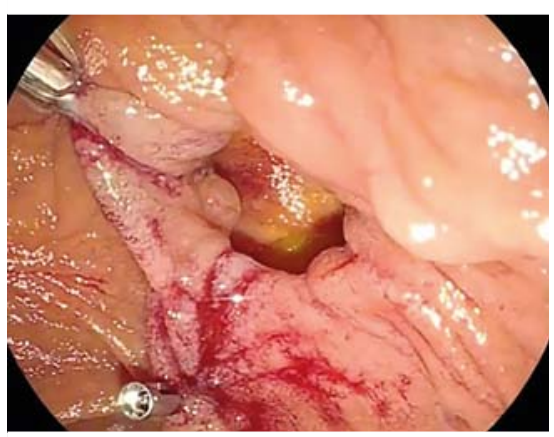

Fig. 2 Elastic-band traction technique with metallic clip of intradiverticular papilla.

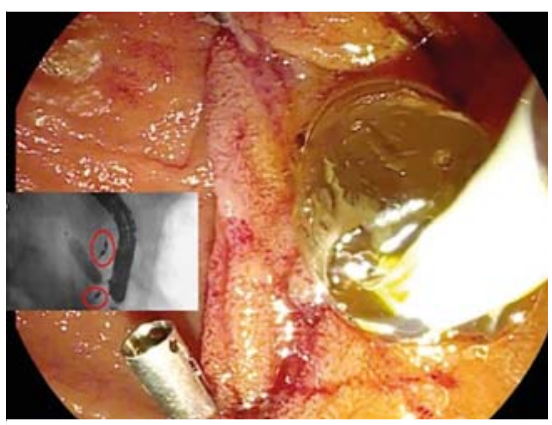

- Fig. 3 Endoscopic and radioscopic view of papilla dilation.

An 84-year-old man attended the emergency department because of jaundice, fever, and abdominal pain. Blood tests showed an increase in conjugated bilirubin and cholestasis markers. He un-

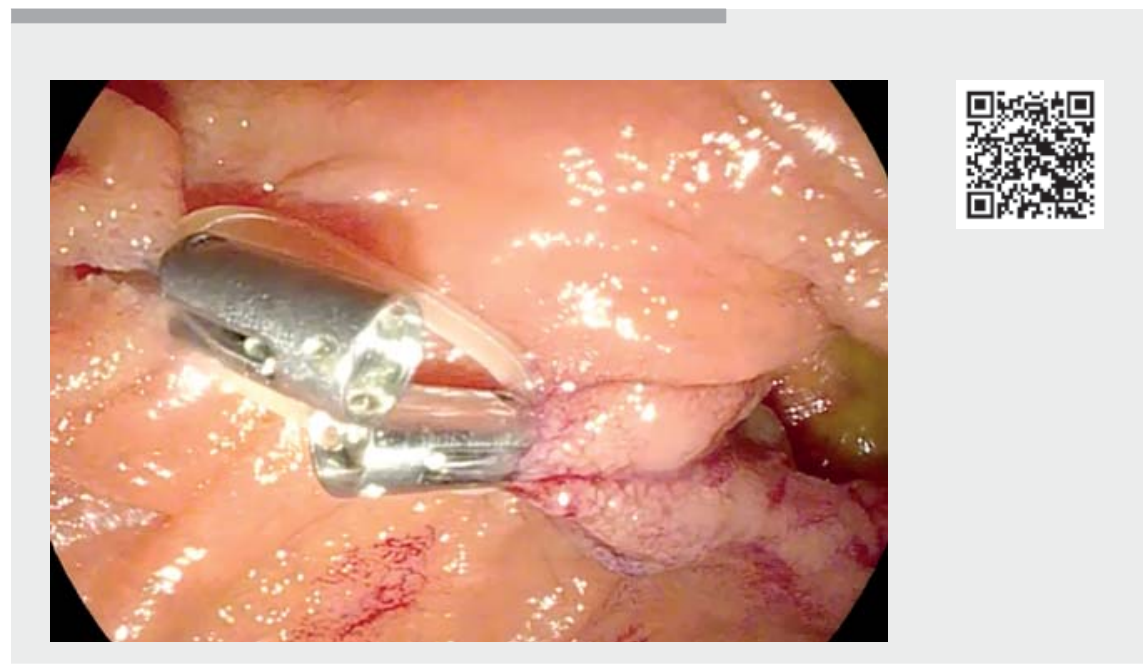

Video 1 The technique of elastic-band traction for cannulation of an intradiverticular papilla during endoscopic retrograde cholangiopancreatography.

derwent abdominal ultrasound, which revealed common bile duct dilation $(12 \mathrm{~mm}$ in size) and the presence of several bile stones. Diagnosis of acute cholangitis was made [1] and he underwent urgent therapeutic endoscopic retrograde cholangiopancreatography (ERCP), according to guidelines [2].

During the procedure, a large diverticulum with deep intrapapillary Vater's papilla was found, making papillary cannulation impossible ( $\triangleright$ Fig. 1). After several cannulation attempts using both $20 \mathrm{~mm}$ and $25 \mathrm{~mm}$ cutting wire sphincterotomes and different guidewires, together with changes in the patient's position, the endoscopist performed an unusual traction technique to bring the papilla out of the diverticulum and allow visualization of the orifice. A metallic clip with a small dental elastic band attached was placed at the edges of the diverticulum; then, a second metallic clip was attached at the opposite side of the elastic band and fixed to the duodenal mucosa a few centimeters away from the diverticulum. This technique allowed the duodenal fold around the diverticulum to be stretched, exposing the intradiverticular papilla outside the diverticulum. The technique was repeated to allow a second clip to be placed $1 \mathrm{~cm}$ from the first, to provide additional fold stretch ( $\triangleright$ Fig. 2, \ Video 1). As a consequence of this maneuver, the papillary orifice was sufficiently exposed to allow deep bile duct cannulation at the first attempt, with subsequent biliary sphincterotomy and 10-mm balloon papillary dilation and extraction of several biliary stones (> Fig. $\mathbf{3}$ ).

The use of dental elastic bands is common for endoscopic submucosal dissection of gastrointestinal lesions [3]. This case illustrates the use of elastic bands in a traction system during ERCP to expose an intradiverticular papillary orifice and allow bile duct cannulation.

Endoscopy_UCTN_Code_TTT_1AR_2AK

\section{Competing interests}

The authors declare that they have no conflict of interest. 


\section{Ruggero Ponz de Leon Pisani, Giuseppe} Dell’Anna, Francesco Vito Mandarino, Maria Napolitano, Vito Lerna, Giuseppe Cangelli, Pier Alberto Testoni

Division of Gastroenterology and

Gastrointestinal Endoscopy, Department of Experimental Oncology, Vita-Salute San Raffaele University, IRCCS San Raffaele Scientific Institute, Milan, Italy

\section{Corresponding author}

\section{Giuseppe Dell'Anna, MD}

Division of Gastroenterology and Gastrointestinal Endoscopy, Department of Experimental Oncology, Vita-Salute San Raffaele University, IRCCS San Raffaele Scientific Institute, Via Olgettina 60, 20132, Milan, Italy dellanna.giuseppe@hsr.it
[1] Kiriyama S, Kozaka K, Takada T et al. Tokyo Guidelines 2018: diagnostic criteria and severity grading of acute cholangitis (with videos). J Hepatobiliary Pancreat Sci 2018; 25: 17-30

[2] Manes G, Paspatis G, Aabakken L et al. Endoscopic management of common bile duct stones: European Society of Gastrointestinal Endoscopy (ESGE) guideline. Endoscopy 2019; 51: 472-491

[3] Abe S, Wu SYS, Ego M et al. Efficacy of current traction techniques for endoscopic submucosal dissection. Gut Liver 2020; 14: 673-684
Bibliography

Endoscopy 2022; 54: E226-E227

DOI 10.1055/a-1492-2082

ISSN $0013-726 \mathrm{X}$

published online 31.5.2021

(c) 2021. Thieme. All rights reserved.

Georg Thieme Verlag KG, Rüdigerstraße 14, 70469 Stuttgart, Germany

\section{ENDOSCOPY E-VIDEOS}

https://eref.thieme.de/e-videos

回局 Endoscopy E-Videos is an open access online section, 靣话: reporting on interesting cases and new techniques in gastroenterological endoscopy. All papers include a high quality video and all contributions are freely accessible online. Processing charges apply (currently EUR 375), discounts and wavers acc. to HINARI are available.

This section has its own submission website at

https://mc.manuscriptcentral.com/e-videos 